\title{
DESEMPENHO GERMINATIVO DE SEMENTES DE GIRASSOL SUBMETIDAS AO ESTRESSE SALINO
}

\author{
Renan Thiago Carneiro Nunes ${ }^{1 *}$, Aderson Costa Araujo Neto ${ }^{1}$, Ubiratan Oliveira Souza ${ }^{1}$, \\ Otoniel Magalhães Morais ${ }^{2}$
}

\footnotetext{
${ }^{1}$ Programa de Pós-Graduação em Agronomia da Universidade Estadual do Sudoeste da Bahia (UESB), Vitória da Conquista - BA, Brasil. *E-mail: renanthiago_tn@ @otmail.com

${ }^{2}$ Professor Doutor do Departamento de Fitotecnia e Zootecnia da Universidade Estadual do Sudoeste da Bahia (UESB), Vitória da Conquista - BA, Brasil.
}

RESUMO: A condição de estresse salino durante a fase de germinação afeta a emergência das plântulas no campo e, consequentemente, o estande das plantas e o desenvolvimento vegetativo das culturas. Assim, objetivou-se avaliar os efeitos do estresse salino induzido por diferentes condutividades elétricas das soluções de cloreto de sódio $(\mathrm{NaCl})$ e cloreto de cálcio $\left(\mathrm{CaCl}_{2}\right)$ no desempenho germinativo de sementes e vigor de plântulas de girassol da cultivar Catissol. O trabalho foi conduzido em delineamento inteiramente casualizado, em arranjo fatorial $2 \times 6$, com quatro repetições, sendo o primeiro fator constituído pelos sais e o segundo pelos níveis de salinidade: 0,$0 ; 2,5 ; 5,0 ; 7,5 ; 10,0$ e $12,5 \mathrm{dS} \mathrm{m}^{-1}$. Foram avaliadas as seguintes variáveis: germinação, primeira contagem e índice de velocidade de germinação (IVG), plântulas anormais, comprimento e massa seca de plântulas. O desempenho germinativo das sementes de girassol é afetado negativamente pelo estresse salino, principalmente, em níveis de salinidade a partir de $6,5 \mathrm{dS} \mathrm{m}^{-1}$ quando induzido por $\mathrm{NaCl}$. O tratamento com $\mathrm{CaCl}_{2}$ promove efeitos mais severos sobre o crescimento das plântulas, quando comparado ao $\mathrm{NaCl}$, proporcionando a formação de plântulas de girassol menos vigorosas.

Palavras-chave: Helianthus annuиs L. Salinidade. $\mathrm{NaCl} . \mathrm{CaCl}_{2}$.

\section{GERMINATION PERFORMANCE OF SUNFLOWER SEEDS SUBMITTED TO SALT STRESS}

\begin{abstract}
Salt stress during germination affect the emergence of seedlings in the field and, consequently, the stand of the plants and crop growth. The objective was to evaluate the effects of salt stress induced by different electrical conductivities of solutions of sodium chloride $(\mathrm{NaCl})$ and calcium chloride $\left(\mathrm{CaCl}_{2}\right)$ on the germination performance of seeds and seedling vigor of sunflower cultivar Catissol. The work was conducted in a completely randomized design in factorial $2 \times 6$, with four replications, the first factor consisting of the salts and the second the salinity levels: $0.0 ; 2.5 ; 5.0 ; 7.5 ; 10.0$ and $12.5 \mathrm{dS} \mathrm{m}^{-1}$. The following variables were evaluated: germination, first count and germination speed index (GSI), abnormal seedling, length and dry mass of seedlings. Germination performance of sunflower seeds is negatively affected by salt stress mainly on salinity levels from $6.5 \mathrm{dS} \mathrm{m}^{-}$

${ }^{1}$ when induced by $\mathrm{NaCl}$. The $\mathrm{CaCl}_{2}$ treatment promotes more severe effects on seedling
\end{abstract}


growth, as compared to $\mathrm{NaCl}$, the formation providing less vigorous sunflower seedlings.

Key words: Helianthus annuus L.. Salinity. $\mathrm{NaCl}$. $\mathrm{CaCl}_{2}$.

\section{INTRODUÇÃO}

O girassol (Helianthus annuus L.), juntamente com a soja e a canola, apresenta grande importância na economia mundial, sendo uma das três mais importantes culturas anuais produtoras de óleo do mundo. As perspectivas de crescimento da área cultivada com esta espécie são bastante favoráveis e vêm aumentando em diversas regiões do Brasil (BARROS; ROSSETTO, 2009), visando atender o mercado de óleos comestíveis nobres, produção de silagem e de mel, além do ramo de flores ornamentais (EMBRAPA, 2008). Outro fator é alto teor de óleo no grão, que varia de 40 a 54\%, dependendo da cultivar e do ambiente de cultivo (ROSSI, 1998). Assim, o girassol desponta como uma nova opção para a produção de biocombustíveis (BALBINOT JUNIOR et al., 2009).

Entretanto, há fatores ambientais, denominados estresses ou distúrbios ambientais, que limitam a produtividade agrícola, inclusive a da cultura do girassol (ASHRAF; HARRIS, 2004; CARNEIRO et al., 2011). A salinidade é um dos mais importantes fatores de estresse abiótico, afetando diversos aspectos da fisiologia e bioquímica das plantas, reduzindo significativamente seus rendimentos. Altas concentrações exógenas de sal afetam a germinação das sementes, causando déficit hídrico e desequilíbrio iônico nas células, resultando em toxicidade e estresse osmótico (KHAN; PANDA, 2008).

A intensidade com que o estresse salino afeta a germinação depende primordialmente de um conjunto de fatores relacionados à semente (vigor, forma e morfologia da testa), ao tipo de sal (concentração salina e tempo de exposição), bem como as condições ambientais as quais a semente esta sujeita (temperatura, luminosidade, oxigênio e umidade relativa do ar) (WAHID et al., 1999). Além disso, nas glicófitas, em que se encontram a maioria das plantas cultivadas, a etapa de estabelecimento da plântula é mais afetada pela salinidade do que a de germinação (MARQUES et al., 2011).

A resistência à salinidade é descrita como a habilidade das plantas de evitar, por meio de uma regulação salina, que excessivas quantidades de sal provenientes do substrato alcancem o protoplasma, e também, de tolerar os efeitos tóxicos e osmóticos associados ao aumento da concentração de sais. Essa adaptação das plantas ao estresse vem sendo avaliada pela capacidade germinativa das sementes e pela análise de crescimento (CONUS et al., 2009). De acordo com Góis et al. (2008) a redução do poder germinativo, em comparação ao controle, serve como um indicador do grau de tolerância da espécie à salinidade. Em estudo desta natureza, Dickmann et al. (2005) concluíram que a cultura do girassol enquadra-se como pouco tolerante à salinidade, podendo sofrer reduções progressivas de germinação e vigor das plântulas com o aumento da concentração de sais no meio radicular.

Estudos com sementes têm sido conduzidos sob condições de deficiência hídrica usando soluções salinas para simular um ambiente com pouca umidade, sendo o efeito 
dependente tanto do sal utilizado, em um mesmo grau de deficiência de água, podendo-se citar o $\mathrm{CaCl}_{2}, \mathrm{KCl}, \mathrm{NaCl}$ e $\mathrm{MgCl}_{2}$ (MORAES et al., 2005; BENEDITO et al., 2008; OLIVEIRA; GOMES-FILHO, 2009; DEUNER et al., 2011); como da espécie, por exemplo, soja (MORAES; MENEZES, 2003; MACHADO NETO et al., 2004), feijão (DANTAS et al., 2007; CUSTÓDIO et al., 2009; COELHO et al., 2010) e milho (MOTERLE et al., 2006; CONUS et al., 2009).

Por ser cultivada em segunda época ou safrinha, a cultura do girassol está frequentemente sujeita a condições climáticas desfavoráveis ao seu desenvolvimento (DICKMANN et al., 2005), em especial a disponibilidade hídrica e o nível de salinidade do solo, por ocasião da semeadura (BACKES et al., 2008). Assim, o estudo da capacidade germinativa das sementes de girassol sob diferentes níveis de salinidade nos dará ideia do comportamento desta espécie em condições desfavoráveis para a germinação e o estabelecimento em campo.

Diante do exposto, considerando que a salinidade é um fator limitante para a cultura do girassol, objetivou-se avaliar os efeitos do estresse salino induzido por diferentes condutividades elétricas das soluções de cloreto de sódio $(\mathrm{NaCl})$ e cloreto de cálcio $\left(\mathrm{CaCl}_{2}\right)$ no desempenho germinativo e vigor de plântulas de girassol da cultivar Catissol.

\section{MATERIAL E MÉTODOS}

O trabalho foi conduzido no Laboratório de Tecnologia de Sementes da Universidade Estadual do Sudoeste da Bahia, Campus de Vitória da Conquista, BA, em fevereiro de 2015, com sementes de girassol (Helianthus annus L.), cultivar Catissol (safra 2014), adquiridas junto ao Departamento de Sementes, Mudas e Matrizes (DSMM) da Coordenadoria de Assistência Técnica Integral (CATI), em Campinas, SP.

Para a promoção do estresse salino foram preparadas soluções de cloreto de sódio $(\mathrm{NaCl})$ e cloreto de cálcio $\left(\mathrm{CaCl}_{2}\right)$, as quais foram calibradas, em condutivímetro "Digimed" modelo DM-31, para as seguintes condutividades elétricas (CE): 0,0 (água destilada); 2,5; 5,$0 ; 7,5 ; 10$ e $12,5 \mathrm{dS} \mathrm{m}^{-1}$ (Tabela 1 ).

Tabela 1. Concentrações de $\mathrm{NaCl}$ e $\mathrm{CaCl}_{2}$ para se obter diferentes condutividades elétricas da solução de embebição.

\begin{tabular}{ccc}
\hline $\begin{array}{c}\text { Condutividade elétrica } \\
\left(\mathrm{dS} \mathrm{m}^{-1}\right)\end{array}$ & $\mathrm{NaCl}$ & $\mathrm{CaCl}_{2}$ \\
\cline { 2 - 3 } 0,0 & 0 & 0 \\
2,5 & 1,37 & 1,92 \\
5,0 & 2,73 & 3,83 \\
7,5 & 4,10 & 5,75 \\
10,0 & 5,46 & 7,66 \\
12,5 & 6,83 & 9,58 \\
\hline
\end{tabular}

Cultura Agronômica, Ilha Solteira, v.25, n.1, p.79-92, 2016 
O teste de germinação consistiu em colocar quatro repetições de 50 sementes, envolvidas entre três folhas de papel Germitest ${ }^{\circledR}$, sendo duas como base e uma para cobrir, umedecidas com 2,5 vezes a sua massa com as soluções mencionadas anteriormente. Em seguida, os rolos foram envolvidos em sacos de polietileno e mantidos em germinador tipo Biochemical Oxigen Demand (B.O.D.), com fotoperíodo de oito horas e regulado à temperatura constante de $25^{\circ} \mathrm{C}$.

Os efeitos do estresse salino sobre a qualidade fisiológica das sementes foram avaliados conforme as variáveis descritas a seguir:

a) Primeira contagem da germinação - realizada simultaneamente com o teste de germinação, computando-se a porcentagem acumulada de plântulas normais no quarto dia após a instalação do ensaio, conforme recomendado por Brasil (2009).

b) Germinação - avaliada aos dez dias após a semeadura, por ocasião do final do experimento, sendo os resultados expressos em porcentagem média de plântulas normais (BRASIL, 2009).

c) Índice de velocidade de germinação (IVG) - determinado mediante contagem diária das plântulas normais, sendo o índice calculado pela fórmula proposta por Maguire (1962), onde: $\mathrm{IVG}=\left(\mathrm{G}_{1} / \mathrm{N}_{1}\right)+\left(\mathrm{G}_{2} / \mathrm{N}_{2}\right)+\left(\mathrm{G}_{3} / \mathrm{N}_{3}\right)+\ldots+\left(\mathrm{G}_{\mathrm{n}} / \mathrm{N}_{\mathrm{n}}\right)$, sendo: $\mathrm{G}_{1}, \mathrm{G}_{2}, \mathrm{G}_{3}, \ldots, \mathrm{G}_{\mathrm{n}}=$ número de plântulas computadas na primeira, segunda, terceira e última contagem; $N_{1}, N_{2}, N_{3}, \ldots, N_{n}$ = número de dias da semeadura à primeira, segunda, terceira e última contagem.

d) Plântulas anormais - porcentagem de plântulas com alguma anormalidade em uma de suas estruturas essenciais, que inviabilizaria seu desenvolvimento (BRASIL, 2009), computando-se ao final do teste de germinação.

e) Comprimento de plântulas - ao final do teste de germinação, as plântulas normais de cada repetição foram utilizadas para avaliar o comprimento (da extremidade radicular até a inserção dos cotilédones), com o auxílio de uma régua graduada em centímetros, sendo os resultados expressos em centímetros por plântula.

f) Massa de matéria seca de plântulas - ao final do teste de germinação, as plântulas, provenientes da avaliação do comprimento, foram colocadas em sacos de papel do tipo Kraft e acondicionadas em estufa com circulação de ar forçado, regulada a $65^{\circ} \mathrm{C}$, onde permaneceram até atingir massa constante. Em seguida, foram pesadas em balança analítica com precisão de $0,001 \mathrm{~g}$, sendo os resultados expressos em gramas por plântula.

O delineamento experimental adotado foi o inteiramente casualizado, em esquema fatorial $2 \times 6$, sendo dois indutores de salinidade e seis níveis de salinidade, com quatro repetições de 50 sementes para cada tratamento. Os dados foram submetidos à análise de homogeneidade das variâncias (teste de Bartlett) e de normalidade (Lilliefors). Em seguida, foi realizada análise de variância e para a comparação das médias utilizou-se o teste de Tukey, a 5\% de probabilidade. Para os efeitos quantitativos foi realizada análise de regressão polinomial, selecionando-se o modelo de maior grau significativo. 


\section{RESULTADOS E DISCUSSÃO}

Dentre as variáveis avaliadas, verificou-se interação entre os sais e os níveis de salinidade $(\mathrm{p}<0,05)$ apenas para a variável percentual de plântulas anormais e o comprimento de plântulas. Para a germinação constatou-se efeito isolado destes fatores, enquanto que para o índice de velocidade de germinação (IVG) e a massa seca de plântulas houve somente efeito dos níveis de salinidade. Já para a primeira contagem da germinação não houve efeito significativo destes fatores.

O desempenho germinativo das sementes manteve-se inalterado até a condutividade estimada de $6,5 \mathrm{dS} \mathrm{m}^{-1}$, apresentando resultados acima de $95 \%$, o que pode ser um indicativo de tolerância do girassol cv. Catissol até níveis moderados de salinidade. Entretanto, com o aumento da concentração salina no substrato houve decréscimo no percentual de germinação, obtendo-se os menores resultados em $12,5 \mathrm{dS} \mathrm{m}^{-1}$, representando uma redução de aproximadamente $15 \%$ em relação à testemunha $\left(0 \mathrm{dS} \mathrm{m}^{-1}\right)$ (Figura 1A); evidenciando o efeito negativo do estresse salino sobre a germinação e o desenvolvimento inicial das plântulas de girassol.
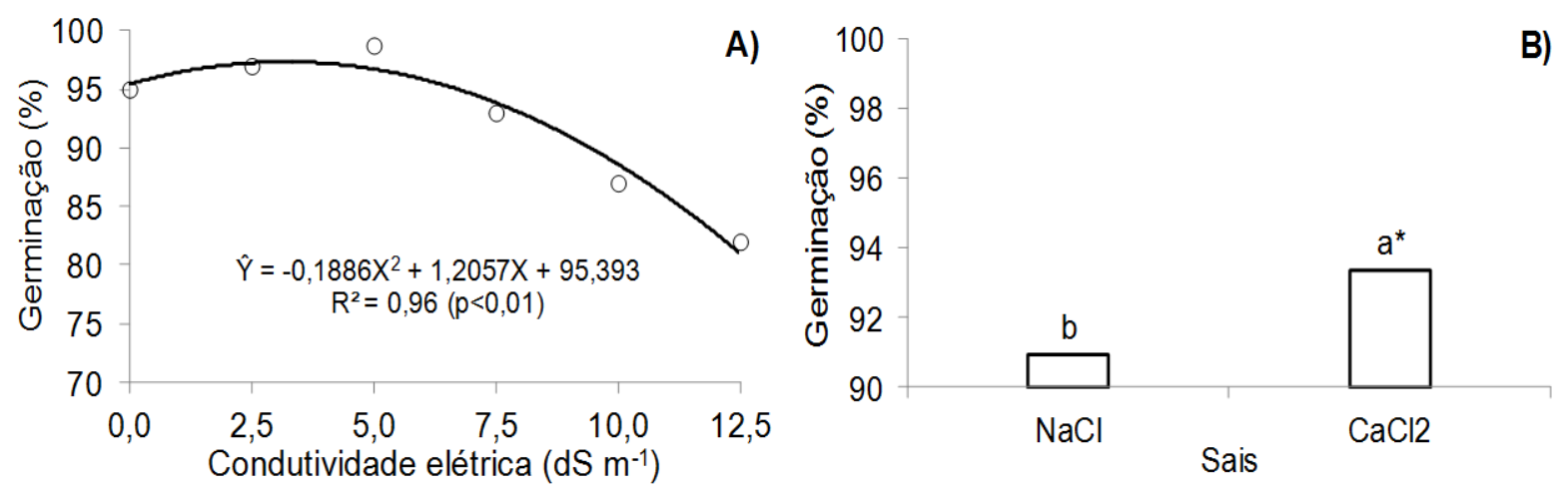

*Colunas seguidas de mesma letra não diferem entre si pelo teste de Tukey a 5\% de probabilidade.

Figura 1. Germinação de sementes de girassol da cultivar Catissol submetidas ao estresse salino (A) induzido por soluções de $\mathrm{NaCl}$ e $\mathrm{CaCl}_{2}$ (B) com diferentes condutividades elétricas.

Esses resultados têm sido atribuídos à redução da quantidade de água absorvida pelas sementes em meio salino, com a redução do potencial osmótico das soluções (BRACCINI $e t$ al., 1996). Segundo O’leary (1995) a ocorrência excessiva de sais solúveis no substrato acarreta redução do potencial osmótico e, como consequência, redução do gradiente de potencial hídrico entre o substrato e a semente, dificultando o processo de embebição e comprometendo a germinação. Contudo, Tobe et al. (2000) afirmam que a inibição da germinação ocasionada pela salinidade se deve tanto ao efeito osmótico, ou seja, à "seca fisiológica" produzida, como ao efeito tóxico, resultante da concentração de íons no protoplasma.

Resultados semelhantes foram encontrados por Sousa et al. (2012a,b) em sementes de duas cultivares de girassol (BRS 321 e BRS 324), confirmando a redução da germinação 
com o aumento da concentração salina no substrato $\left(0,0 ; 1,0 ; 2,0 ; 3,0\right.$ e 4,0 dS m${ }^{-1}$ de $\left.\mathrm{NaCl}\right)$. Avaliando o processo germinativo de três cultivares de girassol (MG2, MG50 e M734) em relação ao potencial osmótico da solução e dois tipos de sais $\left(\mathrm{NaCl}\right.$ e $\left.\mathrm{CaCl}_{2}\right)$, Dickmann et al. (2005) constataram que aumento do potencial osmótico das soluções salinas produziu um decréscimo na germinação e vigor das plântulas, podendo esta espécie ser incluída entre as glicófilas pouco tolerantes a salinidade.

Em contrapartida, Carneiro et al. (2011) concluíram que o estresse salino até os níveis de potencial osmótico de $-0,4 \mathrm{MPa}\left(\cong 11,2 \mathrm{dS} \mathrm{\textrm {m } ^ { - 1 }}\right)$ de $\mathrm{NaCl}$ não afeta o desempenho fisiológico da cultivar de girassol M735. Enquanto Nobre et al. (2012), em concordância com os resultados obtidos, verificaram que níveis salinos variando de 0,5 a 4,9 dS m $\mathrm{m}^{-1}$ não afetam a percentagem de emergência do girassol Embrapa 122/V-2000. Tal fato demonstra que o estresse salino apresenta efeitos bastante variáveis, pois de acordo com Lacerda et al. (2006), a tolerância à salinidade varia entre espécies, entre variedades/genótipos de uma mesma espécie e até mesmo entre estádios fenológicos de um mesmo genótipo.

Quanto à comparação entre os sais (Figura 1B), verificou-se que o tratamento com $\mathrm{NaCl}$ foi mais drástico em relação ao $\mathrm{CaCl}_{2}$, promovendo redução no percentual de germinação. Tal fato pode estar relacionado ao efeito tóxico decorrente do acúmulo excessivo de íons $\mathrm{Na}^{+}$e $\mathrm{Cl}^{-}$, responsável pela inibição da depleção das reservas cotiledonares e o crescimento do eixo embrionário, daí o menor percentual de germinação das sementes no tratamento com $\mathrm{NaCl}$. Ashraf et al. (2003) também observaram o acúmulo gradual dos íons $\mathrm{Na}^{+}$e $\mathrm{Cl}^{-}$, e a consequente redução do íon $\mathrm{K}^{+}$, nos cotilédones e no hipocótilo de plântulas de girassol submetidas a concentrações crescentes de $\mathrm{NaCl}(0,50$, 100 e $150 \mathrm{mM}$ ), que se relacionaram a inibição da mobilização de reservas cotiledonares nessa espécie.

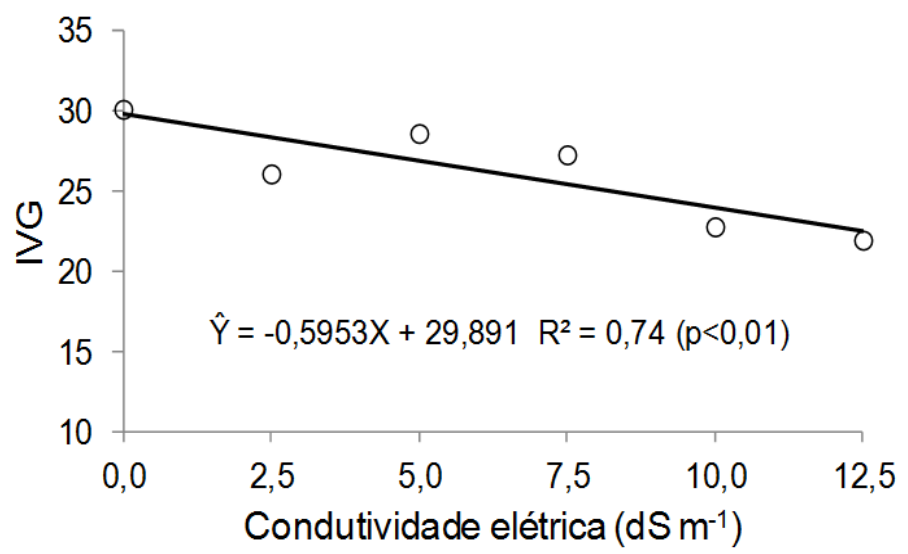

Figura 2. Índice de velocidade de germinação (IVG) de sementes de girassol da cultivar Catissol submetidas ao estresse salino.

Em relação ao índice de velocidade de germinação (Figura 2), observou-se decréscimo progressivo do índice à medida que se aumentou a concentração salina no substrato, com os maiores valores registrados na testemunha $\left(0 \mathrm{dS} \mathrm{m^{-1 }}\right)(30,15)$ e os menores na condutividade de $12,5 \mathrm{dS} \mathrm{m} \mathrm{m}^{-1}(21,9)$; demonstrando que o estresse salino retarda a germinação das sementes de girassol. A explicação para este comportamento é devido às condições salinas, 
ocorrendo redução do potencial osmótico do meio, e consequentemente, aumento do tempo de embebição de água pelas sementes, ocasionando o prolongamento do processo germinativo (MARQUES et al., 2011).

Dantas et al. (2007) complementam afirmando que a velocidade de germinação das sementes e o estabelecimento das plântulas são afetados em virtude do fato da salinidade reduzir o potencial hídrico da semente em relação ao solo. Assim há o atraso na mobilização de enzimas responsáveis pela germinação, além dos efeitos tóxicos dos sais sobre os tecidos vivos e do retardamento na síntese da enzima $\alpha$-amilase cotiledonar.

De acordo com Oliveira e Gomes-Filho (2009) o incremento na concentração de $\mathrm{NaCl}$ $\left(7,5 ; 10,5 ; 22,5\right.$ e $\left.30,0 \mathrm{dS} \mathrm{m}^{-1}\right)$ do substrato promoveu um maior decréscimo na velocidade de germinação de sementes de sorgo forrageiro, representada pela redução no índice de velocidade de germinação. Atraso na germinação de sementes ocasionado pelo excesso de sais também foi observado por outros autores em diversas culturas de importância econômica, como soja, milho e feijão (MORAES; MENEZES, 2003; MOTERLE et al., 2006; DANTAS et al., 2007).

$\mathrm{Na}$ avaliação de plântulas anormais na condição de estresse salino (Figura 3), observou-se que o tratamento com $\mathrm{CaCl}_{2}$ proporcionou sensível redução no percentual de plântulas anormais com o aumento do nível de salinidade no substrato, atingindo $1 \% \mathrm{em}$ $12,5 \mathrm{dS} \mathrm{m}{ }^{-1}$. Entretanto, para o $\mathrm{NaCl}$ verificou-se aumento progressivo na formação de plântulas anormais, evidenciado, principalmente, a partir da condutividade de $5,0 \mathrm{dS} \mathrm{m}^{-1}$, obtendo-se maior percentual em 12,5 dS m $\mathrm{d}^{-1}(16 \%)$; demonstrando que em concentrações mais elevadas, o estresse salino induzido por $\mathrm{NaCl}$ promove o aumento da ocorrência de plântulas anormais de girassol. Resultados semelhantes foram obtidos por Machado Neto et al. (2004), ao constatarem elevados percentuais de plântulas anormais de cultivares de soja no potencial de $-1,2 \mathrm{MPa}\left(\cong 33,3 \mathrm{dS} \mathrm{m}^{-1}\right)$, quando submetidas ao estresse salino induzido por $\mathrm{NaCl}$.

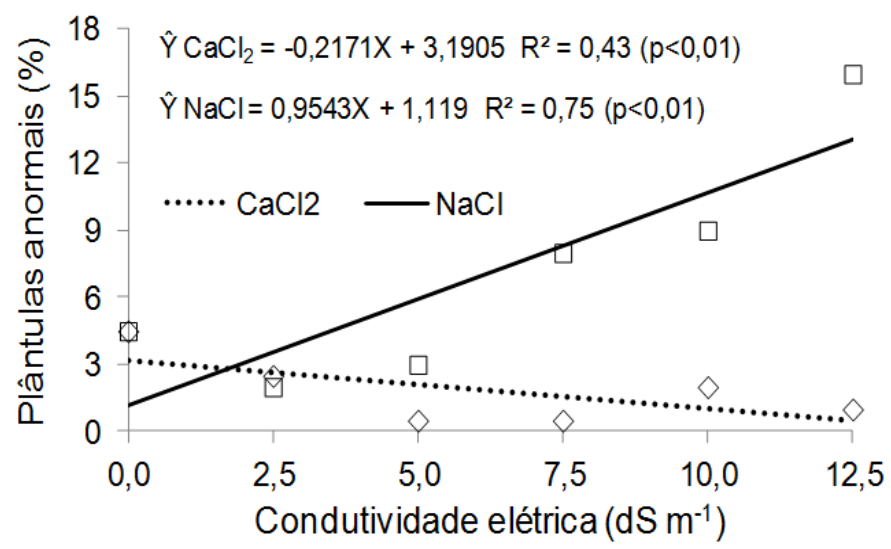

Figura 3. Plântulas anormais de girassol da cultivar Catissol oriundas de sementes submetidas ao estresse salino induzido por soluções de $\mathrm{NaCl}$ e $\mathrm{CaCl}_{2}$ com diferentes condutividades elétricas.

Cultura Agronômica, Ilha Solteira, v.25, n.1, p.79-92, 2016 
Para o comprimento de plântulas (Figura 4), verificou-se que o $\mathrm{NaCl}$ e o $\mathrm{CaCl}_{2}$ apresentaram comportamento semelhante durante o estresse salino. Esta variável, decresceu à medida que houve aumento da concentração salina no substrato, sendo os maiores valores registrados nas plântulas formadas a partir das sementes da testemunha $\left(0 \mathrm{dS} \mathrm{m} \mathrm{m}^{-1}\right)(18,0 \mathrm{e}$ $17,8 \mathrm{~cm}$, respectivamente) e os menores a partir de sementes submetidas a condutividade de $12,5 \mathrm{dS} \mathrm{m}^{-1}$ (12,0 e 7,0 cm, respectivamente). Desta forma, elevadas concentrações salinas comprometem significativamente o comprimento das plântulas de girassol.

Essa mesma tendência também foi observada por Moterle et al. (2006), ao verificarem redução linear no comprimento de plântulas de cultivares de milho-pipoca à medida que o potencial osmótico da solução de $\mathrm{KCl}$ foi diminuído. Em soja, Moraes e Menezes (2003) também constataram redução no comprimento de plântulas à medida que os potenciais osmóticos de $\mathrm{NaCl}, \mathrm{KCl}$ e $\mathrm{MgCl}_{2}$ decresceram, com maior evidência em potenciais inferiores a $-0,2 \mathrm{MPa}\left(\cong 5,6 \mathrm{dS} \mathrm{m}^{-1}\right)$.

Em quatro cultivares de girassol (Helio 863, Embrapa 122/V-2000, Catissol 01 e Multissol), Travassos et al. (2012) verificaram redução drástica da altura de plantas com o incremento da salinidade da água de irrigação $\left(0,6 ; 3,0\right.$ e 5,4 dS m${ }^{-1}$ de $\left.\mathrm{NaCl}\right)$. Nobre et al. (2012) concluíram que o incremento salino $\left(0,5 ; 1,6 ; 2,7 ; 3,8\right.$ e 4,9 dS m m $^{-1}$ de $\mathrm{NaCl}$ ) a partir de $0,5 \mathrm{dS} \mathrm{m}^{-1}$ influenciou, linear e de forma decrescente, a altura de plântulas e a fitomassa seca da parte aérea, aos 10 dias após a semeadura do girassol Embrapa 122/V-2000.

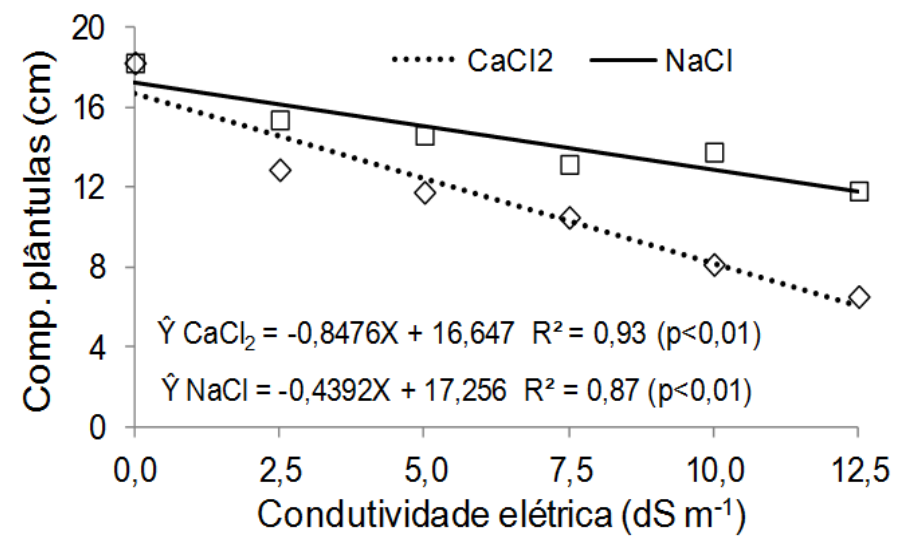

Figura 4. Comprimento de plântulas de girassol da cultivar Catissol oriundas de sementes submetidas ao estresse salino induzido por soluções de $\mathrm{NaCl}$ e $\mathrm{CaCl}_{2}$ com diferentes condutividades elétricas.

Essa redução no comprimento das plântulas se deve às mudanças na turgescência celular, em função da diminuição da síntese de proteína nas condições de estresse hídrico (DELL'ÁQUILLA, 1992). Taiz e Zeiger (2013) relatam que o primeiro efeito mensurável do estresse hídrico é a diminuição no crescimento, causada pela redução da expansão celular.

$\mathrm{Na}$ comparação entre os sais, verificou-se que o $\mathrm{CaCl}_{2}$ proporcionou resultados mais drásticos para o comprimento de plântulas, quando comparado ao $\mathrm{NaCl}$ (Figura 4). Uma possível interpretação para este resultado é que o íon $\mathrm{Ca}^{2+}$ pode promover a modulação de processos celulares por meio de proteínas (calmodulinas), as quais, por sua vez, regulam Cultura Agronômica, Ilha Solteira, v.25, n.1, p.79-92, 2016 
uma cascata de eventos relacionados com as respostas das plantas a estresse biótico e abiótico (YANG; POOVAIAH, 2002), o que poderia ter potencializado a tendência de redução no crescimento das plântulas registrado no tratamento com $\mathrm{CaCl}_{2}$. Contrariando os resultados obtidos, o tratamento com $\mathrm{CaCl}_{2}$ apresentou efeitos menos severos no comprimento da parte aérea e raiz primária de plântulas de milho em relação às soluções de $\mathrm{KCl}$ e $\mathrm{NaCl}$ (CONUS et al., 2009).

Quanto à massa de matéria seca de plântulas (Figura 5), semelhante ao observado no índice de velocidade de germinação (Figura 2), verificou-se redução linear dessa variável com o acréscimo do nível de estresse, obtendo-se os maiores resultados registrados na testemunha $\left(0 \mathrm{dS} \mathrm{m} \mathrm{m}^{-1}\right)(0,45 \mathrm{~g})$ e os menores na condutividade de $12,5 \mathrm{dS} \mathrm{m}^{-1}(0,41 \mathrm{~g})$. Estes resultados demonstram que elevadas concentrações de sal afetam o desenvolvimento normal das plântulas de girassol.

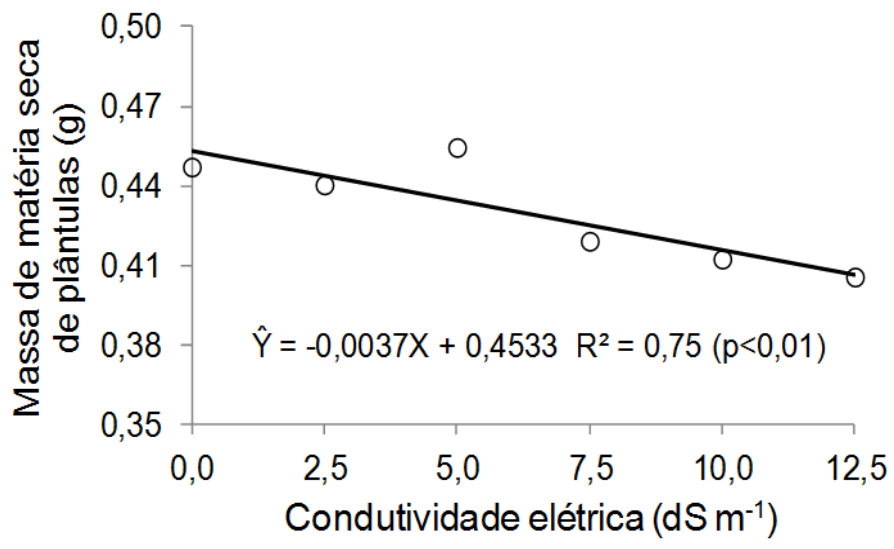

Figura 5. Massa de matéria seca de plântulas de girassol da cultivar Catissol oriundas de sementes submetidas ao estresse salino.

Quando em concentrações mais elevadas, o estresse salino provoca redução no crescimento das plântulas, a exemplo do observado no girassol. Este fator é atribuído à diminuição na absorção de água, seguido por hidrólise limitada de reservas alimentares a partir de tecidos de armazenamento, bem como devido à translocação deficiente dessas reservas para o eixo embrionário em desenvolvimento (KHAN; PANDA, 2008). Contudo, Lacerda et al. (2006) relatam que a redução no comprimento e acúmulo de massa de matéria seca da parte aérea e na raiz, está associada aos efeitos osmóticos, tóxicos e nutricionais decorrentes do acúmulo de sais na zona radicular da plântula.

De maneira geral, o desempenho germinativo do girassol foi afetado negativamente pelo estresse salino, principalmente, em níveis de salinidade acima de $6,5 \mathrm{dS} \mathrm{m}^{-1}$ e quando induzido por $\mathrm{NaCl}$. $\mathrm{O}$ tratamento com $\mathrm{CaCl}_{2}$ acarretou efeitos mais severos sobre o crescimento das plântulas, proporcionando a formação de plântulas menos vigorosas, quando comparado ao $\mathrm{NaCl}$. Os resultados revelam a importância da avaliação dos níveis de salinidade do substrato, considerados críticos para a germinação das sementes e estabelecimento das plântulas de girassol, além da necessidade de se determinar as potencialidades dos diferentes sais na indução do estresse salino, pois de acordo com Conus

Cultura Agronômica, Ilha Solteira, v.25, n.1, p.79-92, 2016 
et al. (2009) as diferenças químicas existentes entre os sais, podem acarretar diferenças nos resultados de germinação e vigor das sementes, mesmo em concentrações salinas similares.

\section{CONCLUSÃO}

O desempenho germinativo das sementes de girassol da cultivar Catissol é afetado negativamente pelo estresse salino, principalmente, em níveis de salinidade acima de 6,5 dS $\mathrm{m}^{-1}$ e quando induzido por $\mathrm{NaCl}$.

$\mathrm{O} \mathrm{CaCl}_{2}$ promove efeitos mais drásticos sobre o crescimento das plântulas, quando comparado ao $\mathrm{NaCl}$, proporcionando a formação de plântulas de girassol da cultivar Catissol menos vigorosas.

\section{REFERÊNCIAS BIBLIOGRÁFICAS}

ASHRAF, M.; HARRIS, P. J. C. Potential biochemical indicators of salinity tolerance in plants. Plant Science, Logan, v. 166, n. 1, p.3-16, 2004.

ASHRAF, M.; ZAFAR, R.; ASHRAF, M. Y. Time-course changes in the inorganic and organic components of germinating sunflower achenes under salt $(\mathrm{NaCl})$ stress. Flora, Jena, v. 198, n. 1, p.26-36, 2003.

BACKES, R. L.; SOUZA, A. M.; BALBINOT JUNIOR, A. A.; GAllOTTI, G. J. M.; BAVARESCO, A. Desempenho de cultivares de girassol em duas épocas de plantio de safrinha no planalto norte catarinense. Scientia Agraria, Curitiba, v. 9, n.1, p.41-48, 2008.

BALBINOT JR.; A. A.; BACKES, R. L.; SOUZA, A. M. Desempenho de cultivares de girassol em três épocas de semeadura no planalto norte catarinense. Scientia Agraria, Curitiba, v. 10, n. 2, p.127-133, 2009.

BARROS, C. S.; ROSSETTO, C. A. V. Teste de germinação sob condições de restrição hídrica para avaliar o vigor de sementes de girassol. Ciência Rural, Santa Maria, v. 39, n. 9, p.2621-2624, 2009.

BENEDITO, C. P.; RIBEIRO, M. C. C.; TORRES, S. B. Salinidade na germinação e no desenvolvimento de plântulas de moringa (Moringa oleiferea Lam.). Revista Ciência Agronômica, Fortaleza, v. 39, n. 3, p.463-467, 2008.

BRACCINI, A. L.; RUIZ, H. A.; BRACCINI, M. C. L.; REIS, M. S. Germinação e vigor de sementes de soja sob estresse hídrico induzido por soluções de cloreto de sódio, manitol e polietileno glicol. Revista Brasileira de Sementes, Londrina, v. 18, n. 1, p.10-16, 1996.

BRASIL, Ministério da Agricultura e Reforma Agrária. Regras para Análise de sementes. Brasília: SNDP/DNDV/CLAV, 2009. 395 p

CARNEIRO, M. M. L. C.; DEUNER, S.; OLIVEIRA, P. V.; TEIXEIRA, S. B.; SOUSA, C. P.; BACARIN, M. A.; MORAES, D. M. Atividade antioxidante e viabilidade de sementes 
de girassol após estresse hídrico e salino. Revista Brasileira de Sementes, Londrina, v. 33, n. 4, p.752-761, 2011.

COElHO, D. L. M.; AGOSTINI, E. A. T.; GUABERTO, L. M.; MACHADO NETO, N. B.; CUSTÓDIO, C. C. Estresse hídrico com diferentes osmóticos em sementes de feijão e expressão diferencial de proteínas durante a germinação. Acta Scientiarum. Agronomy, Maringá, v. 32, n. 3, p.491-499, 2010.

CONUS, L. A.; CARDOSO, P. C.; VENTUROSO, L. R.; SCALON, S. P. Q. Germinação de sementes e vigor de plântulas de milho submetidas ao estresse salino induzido por diferentes sais. Revista Brasileira de Sementes, Londrina, v. 31, n. 4, p.67-74, 2009.

CUSTÓDIO, C. C.; SALOMÃO, G. R.; MACHADO NETO, N. B. Estresse hídrico na germinação e vigor de sementes de feijão submetidas a diferentes soluções osmóticas. Revista Ciência Agronômica, Fortaleza, v. 40, n. 4, p.617-623, 2009.

DANTAS, B. F.; RIBEIRO, L. S.; ARAGÃO, C. A. Germination, initial growth and cotyledon protein content of bean cultivars under salinity stress. Revista Brasileira de Sementes, Londrina, v. 29, n. 2, p.106-110, 2007.

DELL'ÁQUILLA, A. Water uptake and protein synthesis in germinating wheat embryos under osmotic stress of polyethylene glycol. Annals of Botany, Camberra, v. 69, n. 2, p.167-171, 1992.

DEUNER, C.; MAIA, M. S.; DEUNER, S.; ALMEIDA, A. S.; MENEGHELlO, G. E. Viabilidade e atividade antioxidante de sementes de genótipos de feijão-miúdo submetidos ao estresse. Revista Brasileira de Sementes, Londrina, v. 33, n. 4, p.711-720, 2011.

DICKMANN, L.; CARVALHO, M. A. C.; BRAGA, L. F.; SOUSA, M. P. Comportamento de sementes de girassol (Helianthus annuus L.) submetidas a estresse salino. Revista de Ciências Agro-Ambientais, Alta Floresta, v. 3, n.1, p.64-75, 2005.

EMBRAPA. Tecnologia de Produção. Girassol. Exigências climáticas. 2008. Disponível em http://www.cnpso.embrapa.br/producaogirassol/exigencias.html. Acesso em: 20 ago. 2015.

GÓIS, V. A.; TORRES, S. B.; PEREIRA, R. A. Germinação de sementes de maxixe submetidas a estresse salino. Revista Caatinga, Mossoró, v. 21, n. 4, p. 64-67, 2008.

KHAN, M. H.; PANDA, S. K. Alterations in root lipid peroxidation and antioxidative responses in two rice cultivars under NaCl-salinity stress. Acta Physiologiae Plantarum, Bangalore, v. 30, n. 1, p. 81-89, 2008.

LACERDA, C. F.; ASSIS JÚNIOR, J. O.; LEMOS FILHO, L. C. A.; OLIVEIRA, T. S.; GUIMARÃES, F. V. A.; GOMES-FILHO, E.; PRISCO, J. T.; BEZERRA, M. A. Morphophysiological responses of cowpea leaves to salt stress. Brazilian Journal Plant Physiology, Rio de Janeiro, v. 18, n. 4, p.455-465, 2006.

Cultura Agronômica, Ilha Solteira, v.25, n.1, p.79-92, 2016 
MACHADO NETO, N. B.; CUSTÓDIO, C. C.; COSTA, P. R.; DONÁ, F. L. Deficiência hídrica induzida por diferentes agentes osmóticos na germinação e vigor de sementes de feijão. Revista Brasileira de Sementes, Londrina, v. 28, n. 1, p.142-148, 2006.

MACHADO NETO, N. B.; SATURNINO, S. M.; BOMFIM, D. C.; CUSTÓDIO, C. C. Water stress induced by mannitol and sodium chloride in soybean cultivars. Brazilian Archives of Biology and Technology, Curitiba, v. 47, n. 4, p.521-529, 2004.

MAGUIRE, J. D. Speed of germination-aid seedling emergence and vigor. Crop Science, Madison, v. 2, n. 2, p.176-177, 1962.

MARQUES, E. C.; FREITAS, V. S.; BEZERRA, M. A.; PRISCO, J. T.; GOMES-FILHO, E. Efeitos do estresse salino na germinação, emergência e estabelecimento da plântula de cajueiro anão precoce. Revista Ciência Agronômica, Fortaleza, v. 42, n. 4, p.993-999, 2011.

MORAES, G. A. F.; MENEZES, N. L. Desempenho de sementes de soja sob condições diferentes de potencial osmótico. Ciência Rural, Santa Maria, v. 33, n. 2, p.219-226, 2003.

MORAES, G. A. F.; MENEZES, N. L.; PASQUALLI, L. L. Comportamento de sementes de feijão sob diferentes potenciais osmóticos. Ciência Rural, Santa Maria, v. 35, n. 4, p.776-780, 2005.

MOTERLE, L. M.; LOPES, F. C.; BRACCINI, A. L.; SCAPIM, C. A. Germinação de sementes e crescimento de plântulas de cultivares de milho-pipoca submetidas ao estresse hídrico e salino. Revista Brasileira de Sementes, Londrina, v. 28, n. 3, p.169-176, 2006.

NOBRE, R. G.; GHEYI, H. R.; DIAS, N. S.; CORREIA, K. G.; SOARES, F. A. L.; SILVA, G. F. Vigor de sementes de girassol irrigadas com água salobra na fase inicial de crescimento. Revista Brasileira de Ciências Agrárias, Recife, v. 7, n. 3, p.521-526, 2012.

O'LEARY, J. W. Adaptive components of salt tolerance. In: PESSARAKLI, M. (Ed.) Handbook of plant and crop physiology. New York: Marcel Dekker, inc., 1995. p. 577585.

OLIVEIRA, A. B.; GOMES-FILHO, E. Germinação e vigor de sementes de sorgo forrageiro sob estresse hídrico e salino. Revista Brasileira de Sementes, Londrina, v. 31, n. 3, p.48-56, 2009.

ROSSI, R. O. Girassol. Curitiba: Tecnoagro, 1998. 333 p.

SOUSA, J. R. M.; ANJOS SOARES, L. A. D.; SOUSA JÚNIOR, J. R. D.; MAIA, P. D. M. E.; FURTADO, G. D. F.; MARACAJÁ, P. B. Germinação de sementes de girassol cv. BRS 321 umedecidas com solução salina. Agropecuária Científica no Semiárido, Campina Grande, v. 8, n. 1, p.56-60, 2012a.

SOUSA, J. R. M.; ANJOS SOARES, L. A. D.; SOUSA JÚNIOR, J. R. D.; MAIA, P. D. M. E.; SILVA, S. S.; MARACAJÁ, P. B. Germinação de sementes de girassol cv. BRS 324 submetidas a estresse salino simulado por $\mathrm{NaCl}$. Agropecuária Científica no Semiárido, Campina Grande, v. 8, n. 3, p.123-127, 2012b.

Cultura Agronômica, Ilha Solteira, v.25, n.1, p.79-92, 2016 
TAIZ, L.; ZEIGER, E. Fisiologia Vegetal. 5. ed. Porto Alegre: Artmed, 2013. 954 p.

TOBE, K.; LI, X.; OMASA, K. Seed germination and radicle growth of a halophyte, Kalidium caspicum (Chenopodiaceae). Annals of Botany, Oxford, v. 85, n. 3, p.391-396, 2000.

TRAVASSOS, K. D.; GHEYI, H. R.; SOARES, F. A. L.; BARROS, H. M. M.; DIAS, N. S.; UYEDA, C. A.; SILVA, F. V. Crescimento e desenvolvimento de variedades de girassol irrigado com água salina. Irriga, Botucatu, Edição Especial, p. 324-339, 2012.

WAHID, A.; RASUL, E.; RAO, A. R. Germination of seeds and propagules under salt stress. In: PESSARAKLI, M. (Ed.). Handbook of Plant and Crop Stress. 2. ed. New York: Marcel Dekker, Inc., 1999. p. 153-167.

YANG, T.; POOVAIAH, B. W. Hydrogen peroxide homeostasis: activation of plant catalases by calcium/calmodulin. PNAS, Washington, v. 99, n. 6, p.4097-4102, 2002. 
